\title{
Politique
}

Politique

\section{La police. Approche socio-politique de Jean-Louis Loubet del Bayle, Paris, Montchrestien, 1992, 158 p.}

\section{François Armanville}

Numéro 23, hiver 1993

Tendances de la science politique au Québec

URI : https://id.erudit.org/iderudit/040758ar

DOI : https://doi.org/10.7202/040758ar

Aller au sommaire du numéro

Éditeur(s)

Société québécoise de science politique

ISSN

0711-608X (imprimé)

1918-6584 (numérique)

Découvrir la revue

Citer ce compte rendu

Armanville, F. (1993). Compte rendu de [La police. Approche socio-politique de Jean-Louis Loubet del Bayle, Paris, Montchrestien, 1992, 158 p.] Politique, (23), 232-234. https://doi.org/10.7202/040758ar d'utilisation que vous pouvez consulter en ligne.

https://apropos.erudit.org/fr/usagers/politique-dutilisation/ 
La police. Approche socio-politique. de Jean-Louis Loubet del Bayle, Paris, Montchrestien, 1992, $158 \mathrm{p}$.

L'objectif de l'ouvrage de Jean-Louis Loubet del Bayle est de proposer une théorie générale qui vise à combler le vide existant en matière d'observation scientifique du phénomène policier. De façon plus précise, on retrouve dans cet ouvrage un éventail de questions théoriques et d'hypothèses sur les relations existantes entre la police et l'environnement politique et social.

Utilisant de façon simultanée les approches systémique et fonctionnaliste, l'auteur définit l'essence de la fonction policière comme étant au cœur du fonctionnement politique d'une société.

...la police apparait comme une institution spécifique qui se trouve à la jointure, à l'articulation de l'organisation politique et de l'ensemble du système sociétal, et constitue une institution intermédiaire entre le système politique et son environnement sociétal. (p. 32)

Ce rapport interactif est perceptible aussi bien à l'étape des kentrées" (inputs) qu'à celle des "sorties" (outputs) du système. En ce qui concerne les kentrées", la police est susceptible d'intervenir de deux façons, soit par la transmission et la régulation des demandes que l'environnement sociétal adresse au système politique, ou encore comme soutien à celui-ci en l'informant des appuis dont il dispose.

La police peut également avoir une influence directe sur le soutien au système politique. Elle peut agir sur la mobilisation des soutiens ou encore constituer elle-même une source de soutien. Pour Loubet del Bayle, la mobilisation des soutiens se traduit principalement en termes de "socialisation politique". "L'image de la police auprès du public et l'image 
du système politique se trouvent alors en situation d'interaction" (p. 48). Quant à l'analyse de la police comme source de soutien, la fidélité du corps policier devient un des éléments d'appréciation de la solidarité d'un système.

Pour ce qui est des "sorties" (outputs), la police joue un rôle important dans l'exécution et la concrétisation des décisions politiques. Ce rôle est présenté comme étant l'essence de la fonction policière. Cette essence ne se traduit pas seulement en termes de répression, mais également en termes de dissuasion et de persuasion. L'auteur penche ainsi vers la thèse de l' kinsularité" qui fait de l'appareil policier une instance autonome plutôt qu'un exécutant docile et passif envers le système politique.

Cette position amène l'auteur à aborder le thème du contrôle de la police. Le droit, comme élément de contrôle, est décrit comme un élément abstrait et réglementaire ne constituant qu'un point de repère. Le vrai contrôle est plutôt envisagé sous ces deux aspects : il y a le contrôle interne (l'autodiscipline, l'esprit d'équipe, le supérieur hiérarchique, l'organe interne d'inspection) et le contrôle externe (contrôles politique, juridique, administratif et sociétal). Quant au rôle de la presse, il est perçu comme un instrument de contrôle informel.

La dernière partie de l'ouvrage de Jean-Louis Loubet del Bayle porte sur ce que l'analyse systémique appelle les "réalisations", soit les conséquences de l'action du pouvoir politique. II démontre comment la police peut contribuer à transformer les décisions du système politique en biens et en services, lesquels sont distribués à travers le fonctionnement de l'appareil policier.

L'auteur décrit enfin la police comme une institution productrice de sécurité à laquelle se rattache une série d'activités secondaires, voire journalières, telles que le contrôle des accidents, la recherche de personnes disparues, etc. A cette production de biens et services, il ajoute ce qu'Easton appelle les "déclarations connexes", soit le circuit de communication existant entre le système politique et son environnement. Le rôle joué par la police est alors associé de près à la capacité réactive du système politique. La police joue ainsi un rôle de urétroaction" en retournant à l'autorité 
politique l'information sur les conséquences des décisions de ce dernier.

Ne serait-ce qu'à cause du sujet traité, l'ouvrage de Jean-Louis Loubet del Bayle mérite d'être lu par toute personne qui s'intéresse au pouvoir politique et à ses composantes. L'intérêt est d'autant plus grand que les institutions policières sont en voie de transformation. Interpelées par l'opinion publique, elles se voient de plus en plus remises en question sur le plan de leur mode d'intervention et de leur autonomie administrative. Face à ces transformations, il est donc important que les sciences politiques se penchent davantage sur l'étude des institutions policières et, à ce titre, la contribution de Loubet del Bayle est importante.

François Armanville

ENAP - Montréal 